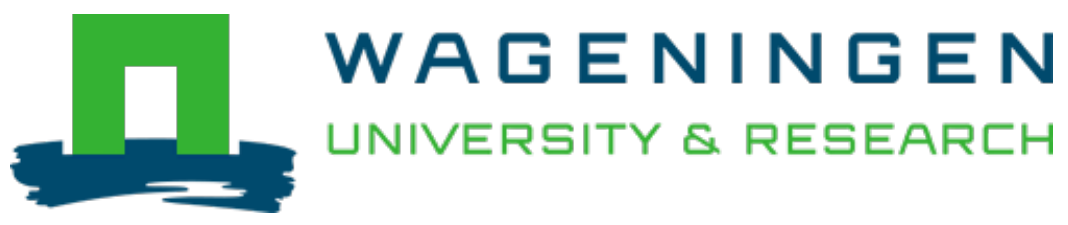

\title{
Fatty acids as cell signals in ingestive behaviors
}

Physiology and Behavior

Figlewicz, Dianne P.; Witkamp, Renger F.

https://doi.org/10.1016/j.physbeh.2020.112985

This article is made publicly available in the institutional repository of Wageningen University and Research, under the terms of article $25 \mathrm{fa}$ of the Dutch Copyright Act, also known as the Amendment Taverne. This has been done with explicit consent by the author.

Article $25 \mathrm{fa}$ states that the author of a short scientific work funded either wholly or partially by Dutch public funds is entitled to make that work publicly available for no consideration following a reasonable period of time after the work was first published, provided that clear reference is made to the source of the first publication of the work.

This publication is distributed under The Association of Universities in the Netherlands (VSNU) 'Article $25 \mathrm{fa}$ implementation' project. In this project research outputs of researchers employed by Dutch Universities that comply with the legal requirements of Article $25 \mathrm{fa}$ of the Dutch Copyright Act are distributed online and free of cost or other barriers in institutional repositories. Research outputs are distributed six months after their first online publication in the original published version and with proper attribution to the source of the original publication.

You are permitted to download and use the publication for personal purposes. All rights remain with the author(s) and / or copyright owner(s) of this work. Any use of the publication or parts of it other than authorised under article $25 \mathrm{fa}$ of the Dutch Copyright act is prohibited. Wageningen University \& Research and the author(s) of this publication shall not be held responsible or liable for any damages resulting from your (re)use of this publication.

For questions regarding the public availability of this article please contact openscience.library@wur.nl 


\title{
FATTY ACIDS AS CELL SIGNALS IN INGESTIVE BEHAVIORS
}

\author{
Dianne P. Figlewicz ${ }^{\mathrm{a}, \mathrm{b}, \mathrm{c}, *}$, Renger F. Witkamp ${ }^{\mathrm{d}}$ \\ ${ }^{a}$ Biomedical Lab Research and Development Service, Veterans Affairs Puget Sound Health Care System, Seattle, WA, USA \\ ${ }^{\mathrm{b}}$ Department of Psychiatry and Behavioral Sciences, University of Washington School of Medicine, Seattle, WA, USA \\ ${ }^{\mathrm{c}}$ VA Northwest Network Mental Illness Research, Education, and Clinical Center, Veterans Affairs Puget Sound Health Care System, Seattle, WA, USA \\ ${ }^{\mathrm{d}}$ Division of Human Nutrition and Health, Wageningen University, The Netherlands
}

\section{A B S T R A C T}

Common dietary fatty acids, including palmitic acid, stearic acid, oleic acid, and polyunsaturated fatty acids, have been studied in the context of overall dietary fat and shown to impact on several types of behaviors, most prominently cognitive behaviors and ingestive behaviors. The independent effects of these fatty acids have been less well-delineated. Several studies implicate these common fatty acids in modulation of the CNS immune/inflammatory response as a key mediator of behavioral effects. However, signaling actions of the fatty acids to regulate cell structure and neuronal or synaptic function have been identified in numerous studies, and the relevance or contribution(s) of these to ingestive behavioral outcomes represent an area for future study. Finally, fatty acids are precursors of endocannabinoids and their structural congeners. Being highly dynamic and complex, the endocannabinoid system plays a key role ingestive behavior via cellular and synaptic mechanisms, thus representing another important area for future study.

\section{INTRODUCTION}

The literature demonstrating the impact of dietary fat on a variety of central nervous system (CNS) functions, including cognition [1-4], and behaviors such as food reward [5,6] and drug reward [7-10] behaviors, has become voluminous over the past few decades. While it would seem intuitively obvious that dietary fat would impact on ingestive behavior, both homeostatic and hedonic in nature, the contributions of specific fatty acid components of dietary fat are only recently beginning to emerge. Such studies are needed because numerous studies showing effects of 'high fat diet feeding' have utilized complex models in which not only high concentrations of multiple fatty acids are used in a diet formulation, but animals may become obese, making it difficult in some studies to differentiate between diet and obesity on behaviors being measured. In this review and perspective, the contributions of fatty acids, particularly from the perspective of dietary fatty acids, to brain and behavioral function will be described and highlighted (see Figure 1 for overview). Table 1 shows the most common fatty acids in the human body (discussed further in [11]). The goal of this perspective is to touch upon findings and data that should lead to new hypotheses, new studies, and new perspectives. Noteworthy omissions include a discussion of dietary fat and fatty acid contributions to the gastrointestinal microbiome, and its downstream influences. This is a significant and rapidly moving field of investigation which could warrant a review in its own right. Further, discussion of 'dietary fat' per se is limited, in order to allow a focus on specific fatty acids which are now appreciated to cause not only unique behavioral outcomes but unique cellular and synaptic effects. Finally, this review focuses upon CNS effects and not upon peripheral endocrine and neural actions, with the goal of critical consideration of CNS actions.

While the digestion and peripheral disposition of ingested fatty acids has been well-characterized, the relationship between ingested fatty acids and altered composition of the numerous classes of lipids in the CNS is complex and not well understood. Thus, there are not one-toone relationships between ingested fatty acids, circulating fatty acids, and brain content of the respective fatty acid. Nonetheless it seems safe to say that the dynamics and concentrations of CNS fatty acid profiles are altered by dietary fat intake $[12,13]$. As an example shown in Figure 2, short-term dietary intakes of palmitic or stearic acids can result in significant changes of fatty acid composition in nuclear fractions from rat brain regions implicated in ingestive and reward behaviors, the hypothalamus and the striatum. Early studies demonstrated rapid accrual of labeled fatty acids including palmitate (following oral or intravenous administration) into brain lipids without being first metabolized to acetate units (see [14] for review). Further, specific fatty acids have specific classes of lipids into which they become incorporated and contribute to CNS function. In addition to in situ brain synthesis of some fatty acids, circulating fatty acids can diffuse across the blood brain barrier, whereupon they become esterified and equilibrate with the existing brain pool of fatty acid-CoA. Fatty acid

\footnotetext{
* Corresponding author. Dianne Figlewicz Lattemann, Ph.D., BLR\&D (151), MIRECC (S-116), VA Puget Sound Health Care System, 1660 So. Columbian Way, Seattle WA 98108, Phone: 206-768-5240

E-mail addresses: latte@uw.edu (D.P. Figlewicz), renger.witkamp@wur.nl (R.F. Witkamp).
} 


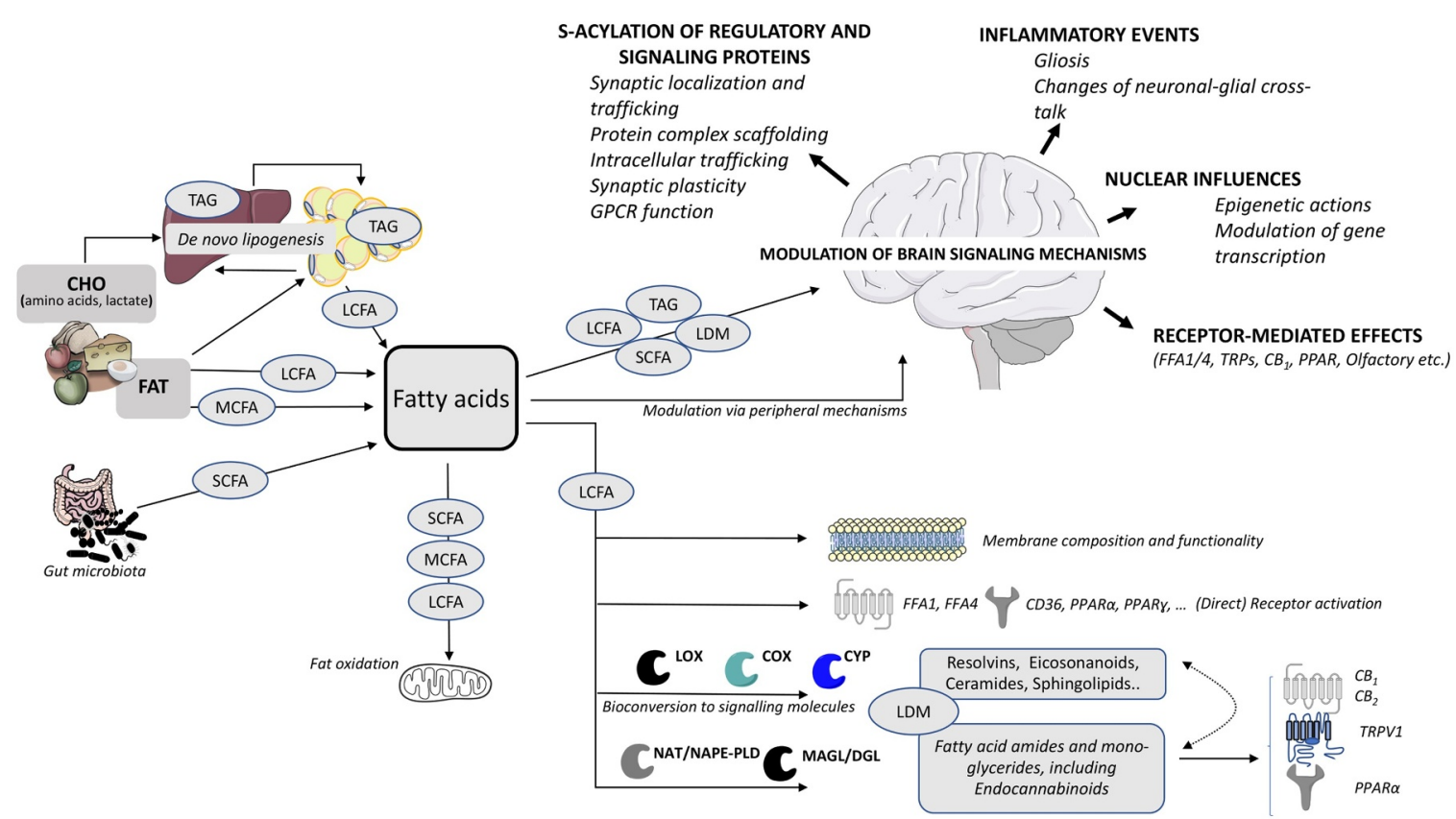

Figure 1. Overview of fatty acid trafficking and biochemical contributions in the body. Ingestion and digestion of dietary fatty acids, and their release into the circulation after transport to and through liver and adipose tissue yields circulating free fatty acids (FFA). De novo lipogenesis takes place in liver and adipose tissue. In the circulation, fatty acids are transported as FFA, as triacyl-glycerol (TAG) and cholesteryl-esters in circulating triglyceride-rich lipoproteins, chylomicrons, very low density lipoproteins (VLDLs) and in erythrocytes. Short-chain fatty acids (SCFA) absorbed from the intestine, and medium chain fatty acids (MCFA) provide signaling at free fatty acid receptive structures, including input to the olfactory system. Long chain fatty acids (LCFA) provide cellular energy, are key structural moieties for stabilization of plasma membranes, and through short and long metabolic conversion loops, are the parent structures for signaling moieties (Lipid-derived mediators; LDM) including eicosanoids, ceramides, sphingolipids, and endocannabinoids. Fatty acids can directly access the central nervous system or as part of TAGs, and there can contribute to cellular and synaptic functions, of which several contribute to the regulation of homeostatic and hedonic feeding behaviors in addition to the feeding-regulatory and energy homeostatic effects of endocannabinoids. Peripheral effects of fatty acids on brain signaling occur via different signaling molecules, including satiety hormones. Additional abbreviations: CHO, carbohydrate; TAG, triacyl-glycerol, triglyceride(s); LDM, lipid-derived mediator(s); GPCR, G-protein coupled receptor; $\mathrm{CB}_{1}$, endocannabinoid type-1 receptor; $\mathrm{CB}_{2}$, endocannabinoid type-2 receptor; PPAR, peroxisome proliferator-activated receptor (type alpha or gamma); TRP(s); transient receptor potential receptor(s); TRPV1, transient receptor potential vanilloid type 1; FFA1-4, long-chain fatty acid, GPCR receptor, types 14 (GPR40, 43, 41, 120); LOX, Lipoxygenases; COX, cyclooxygenase; CYP, cytochrome P450 enzyme(s); NAT/NAPE-PLD, NAPE-generating Ca(2+ )-dependent Nacyltransferase/ NAPE-hydrolyzing phospholipase D; MAGL/DGL, monoacylglycerol lipase/ diacylglycerol lipase.

transporters can also facilitate transport. Uptake from plasma does not appear to be selective, and 'transporters' may in fact be linked to trapping or metabolism of the fatty acids [15-17]. The functionality of multiple transport mechanisms continues to be a topic of ongoing discussion [18]; clarification of relevant mechanisms is complicated by experimental limitations, as metabolism of fatty acids may occur rapidly upon penetration of the blood brain barrier. At this juncture it seems reasonable to conclude that regulation or modulation of transport of peripheral fatty acids into the brain can occur at the levels of capillary endothelial membranes, brain cell membranes, and intracellular organelle membranes. One key organelle is the nucleus, and access or transport of fatty acids into the nucleus would contribute to modulatory and/or regulatory action(s) on gene transcription. Indeed, specific transport via transporters or receptors allows numerous classes of lipids (for instance, sphingolipids, inositol lipids, or phospholipids) access to cell nuclei, and the fatty acid composition of these lipids would presumably vary as a result of fatty acid availability. Within the cell nucleus, enzymes are present to metabolize lipids into signaling mediators such as diacylglycerol, arachidonic acid, and ceramide (see [19] for review and discussion). Effects on gene transcription in turn could influence numerous cell processes including metabolism and maintenance of the cell, cell signaling events, and synaptic events. Evidence supports all of these actions, and one challenge is to put together findings from in vitro, cellular, and systems experimental approaches to determine what has in vivo physiological and behavioral significance.

For studies relating to energy homeostasis, 'lipid sensing' has been appreciated for half a century, dating back to research from Oomura and colleagues in the 1970s demonstrating that direct applications of free fatty acids to lateral hypothalamus from rats resulted in changes of electrical activity using unit-recording methodology, within the slices [20]. This argues for fatty acid effects on neuronal function, although direct actions per se might not be determined in a slice preparation. In 1984, lipoprotein lipase (LPL) activity, modulated by nutritional status of the animal, was reported, with hypothalamic LPL being particularly sensitive among brain regions studied [21]. And more recently, LeFoll and colleagues identified CD36 as key for fatty acid sensing [22]. Thus, there are experimental precedents for specific fatty acid effects on energy homeostasis. However, evidence from multiple in vitro and cellular systems supports both critical physiological roles for specific fatty acids, and pathological actions, as well. In vivo CNS evidence for roles of specific fatty acids also comes from the field of cognitive behaviors; delineating cellular and synaptic effects may shed light on mechanisms in common with ingestive behavior circuitry. A frontier for the ingestive behaviors field will be to take these findings, from many other systems, into in vivo and behavioral settings to test their relevance for ingestive behaviors. The value of such studies would be not only clearer understanding of the physiological vs. pathological roles of fatty acids in the diet, but also identification of potential cellular or synaptic mechanisms which might serve as targets for therapeutic consideration, independent of fatty acid effects.

\section{PALMITIC ACID}

The reversible addition of fatty acids to key regulatory proteins intracellularly, with a time course of minutes to hours, S-acylation, is an 
Table 1

Introductory overview of the most common fatty acids in the human body, their major sources of origin, and functions relating to ingestive behaviors. For further information, the reader is referred to the text, and for additional background on lipid biochemistry, also see [11] and the LIPID MAPS website (http://www. lipidmaps.org/).

\section{EXAMPLES MAIN SOURCES FUNCTIONS LINKED WITH \\ INGESTIVE BEHAVIORS}<smiles>CCCCCCCCCCCCCCCCCC(=O)O</smiles>

LONG CHAIN MONO-UNSATURATED FATTY ACIDS (LC-MUFA)<smiles>CCCCCC/C=C/CCCCCCCC(=O)O</smiles><smiles>CCCCCCCC/C=C/CCCCCCCC(=O)O</smiles>

LONG CHAIN POLYUNSATURATED FATTY ACIDS (LC-PUFA)<smiles>CCCCCCCCCCC(=O)O</smiles>

$\begin{array}{ll}\text { Acetic acid (C2) } & \begin{array}{l}\text { Gut microbiota, } \\ \text { endogenous production }\end{array}\end{array}$

Propionic acid (C3) Gut microbiota

Butyric acid (C4)

Octanoic (Caprylic) acid (8:0)

Decanoic (Capric) acid (10:0)

Dodecanoic (Lauric) acid (12:0)

Myristic acid (14:0)

Palmitic acid (16:0)

Stearic acid (18:0)

Oleic acid (18:1 cis-9)
Present in various animal and plant fats. Also endogenously produced (via elongation).

Present in salmon, cod liver oil, macadamia and olive oil, oil from shrub sea buckthorn. Also endogenously produced (elongation and desaturation).

Present in various animaland plant-derived fats and oils, for example olive oil. Also endogenously produced (elongation and desaturation).
Palmitoleic acid (16:1 cis-7)

inoleic acid (18:2n6)
Essential dietary oil to mammals. Present in vegetable oils, nuts, seeds, meats and eggs.
Stimulates FFA2 (GPR43), possibly also in brain, and peripheral FFA3 (GPR41)

Stimulates FFA2 (GPR43), possibly also in brain, and peripheral FFA3 (GPR41)

Probably mainly indirectly via FFA2 (GPR43)

Unknown, possibly indirect metabolic effects

Unknown, possibly indirect metabolic effects

Unknown, possibly indirect metabolic effects

Possible modulation of brain signalling via protein S-acylations ( $c f$ palmitic acid, but less studied).

Important for S-acylation of different regulatory and signalling proteins in brain, epigenetic and transcriptional regulation, modulation of inflammatory processes, direct and indirect (e.g. endocannabinoids, hydroxy-fatty acids etc.) actions on GPCRs, PPARs [see text for further details].

Stearoylation of proteins and histones, most likely via comparable processes as for palmitic acid, though less well investigated. Involved in maintenance of mitochondrial function via (anti-) inflammatory derivatives [see text for further details].

Direct effects on brain signalling so far unknown. Displays peripheral metabolic effects, including via insulin sensitivity and lipogenesis

Found to antagonize, reverse, or prevent palmitate effects. Affects food intake and glucose production after Intracerebroventricular injection. Reported to interact with dopamine signalling in ventral tegmental area. Precursor for the anorexigenic endocannabinoid-like oleoylethanolamine (OEA) [see text for further details].

Agonist of FFA1 (GPR40) and FFA4 (GPR120) in various brain areas.

Precursor of $\mathrm{CB}_{1}$ ligand $N$-dihomo- $\gamma$ -linolenoylethanolamine 


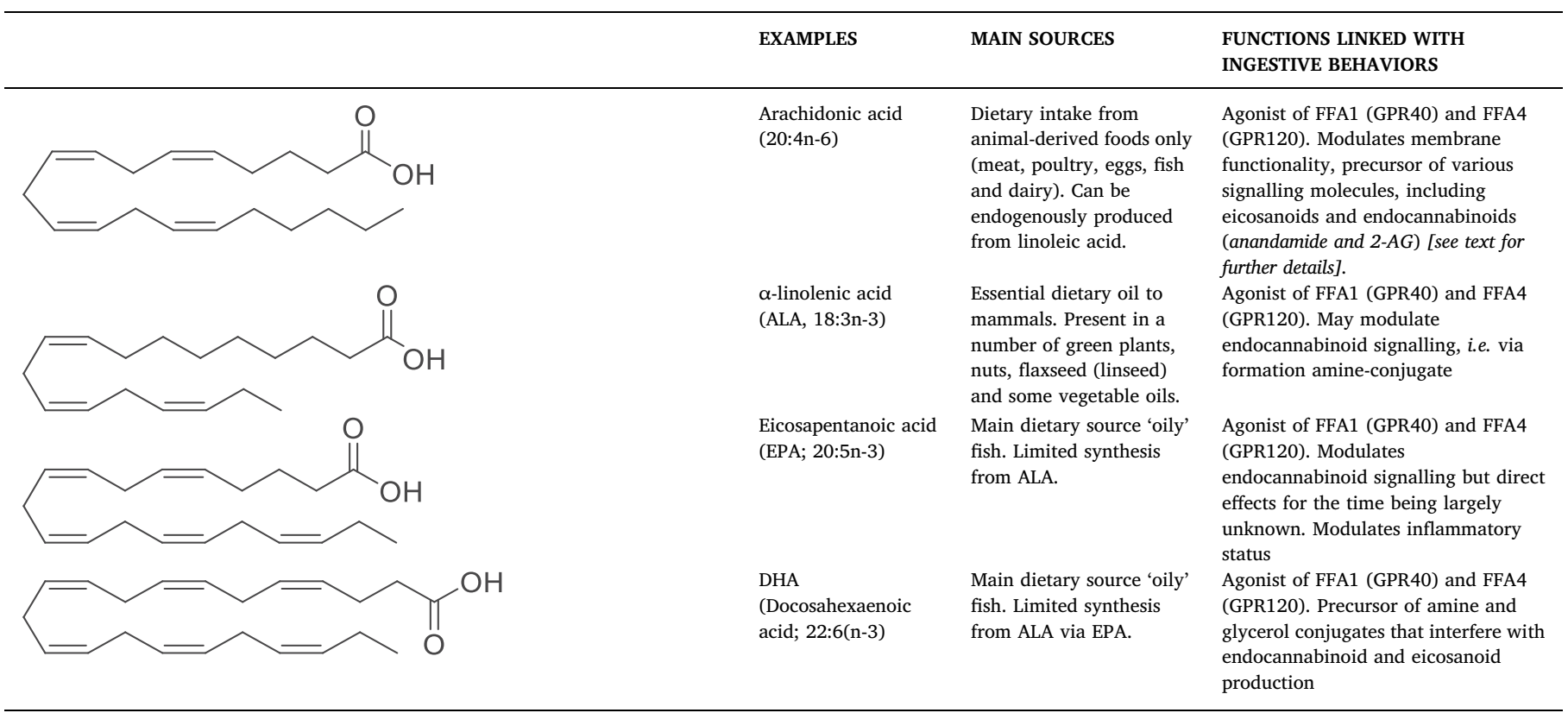
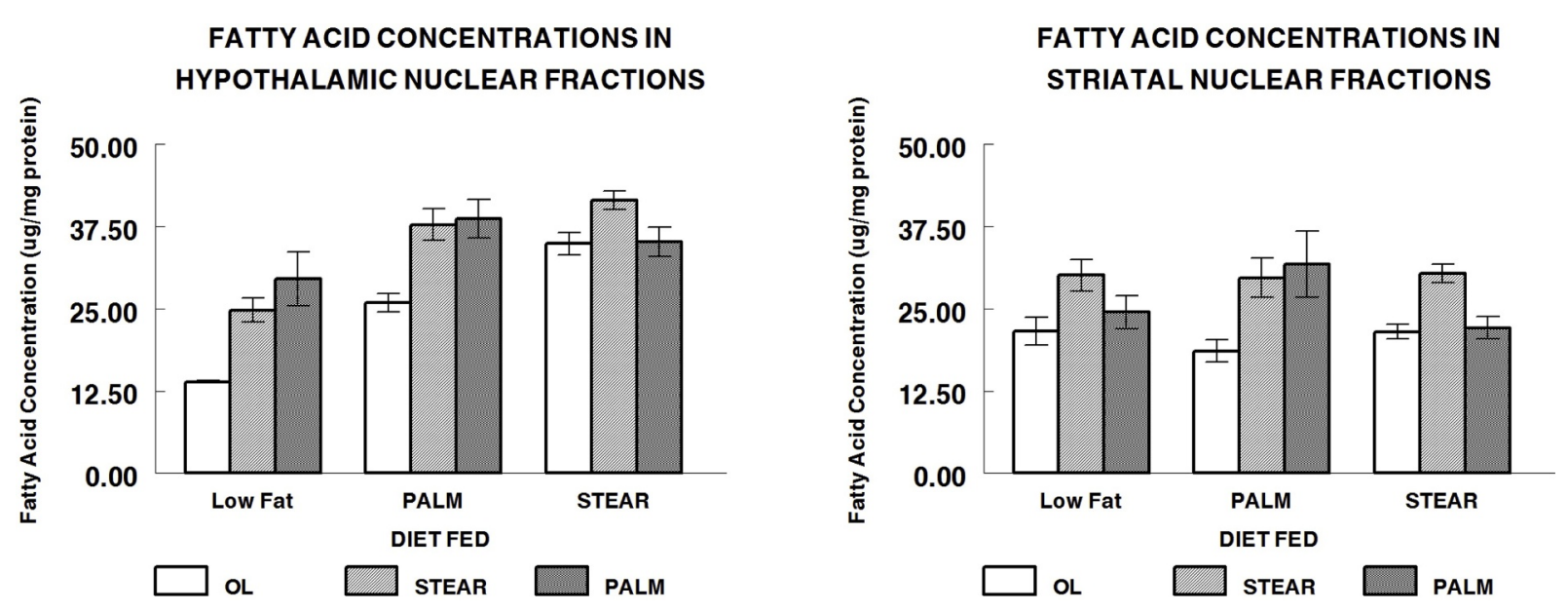

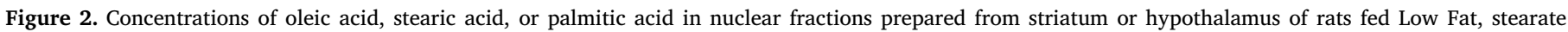

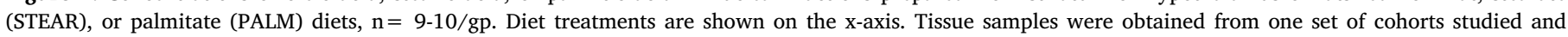

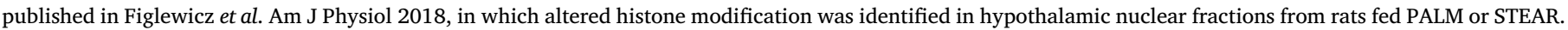

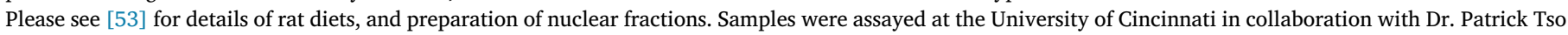

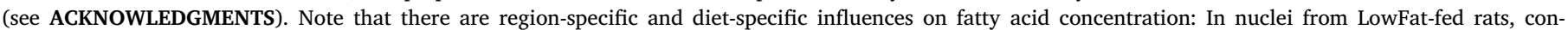

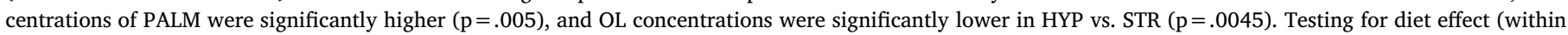

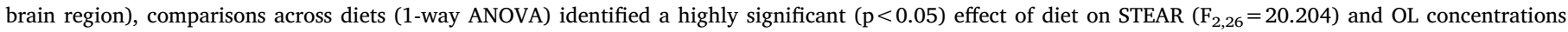

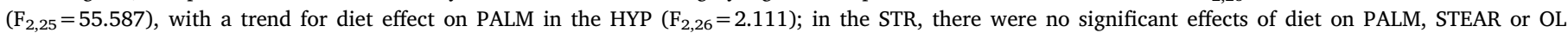

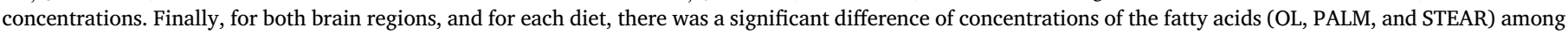
themselves (1-way ANOVA, $\mathrm{p}<0.05$ for all six comparisons).

important process in neuronal and synaptic function. Perhaps best studied is palmitic acid, which is not only a common and highly-present dietary component but also a key intermediary fatty acid in metabolism and cell function. For reviews of S-acylation physiology, the reader is referred to reviews from Chamberlain and colleagues [23,24], Globa and Bamji [25], and Fukata and colleagues [26]. CNS diseases associated with S-palmitoylation processes include Huntington's Chorea, schizophrenia, and Alzheimer's disease (AD) [27]. Both amyloid-precursor protein (APP) [28] and BACE 1 ( $\beta$-Site APP cleaving enzyme 1), a key enzyme for APP processing $[29,30]$, undergo palmitoylation and an age-related increase of palmitoylated APP can result in greater amyloid-B deposition.

Evidence exists for specificity of the S-acyltransferases (DHHCs) for both the fatty acid transferred, and the protein target [31,32]. Of relevance for CNS neuronal circuits that mediate ingestive and reward behaviors, palmitoylation of regulatory proteins plays a role in synaptic transmission, on both sides of the synapse. Candidate neuronal proteins include neurotransmitter receptors, transporters, SNAREs and vesicular trafficking proteins, intracellular scaffolding proteins [33], and the $\mathrm{CB}_{1}$ endocannabinoid receptor [34]. Experimental modifications of specific DHHC enzymes emphasize that one link between increased neuronal activity and increased palmitoylation events is not increased activity of the enzyme, but increased shuttling of a DHHC enzyme to the intracellular locus where it can interact with its substrates (e.g., [35]). The DHHC protein family member, zDHHC9, has recently been identified as essential for dendritic growth and maintenance of excitatory/ 
inhibitory synapse balance, in a mouse knockout model: Behaviorally, the mice manifest increased seizures, leading the authors to speculate that the palmitoylation substrates for DHHC9 may be important targets in epilepsy [36]. A major role for palmitoylation of proteins is the regulation of their trafficking intracellularly and access to the plasma membrane. Some examples of this are described here. Pre-synaptic proteins that regulate synaptic vesicle fusion (e.g., syntaxin 1, SNAP25, and synaptotagmin I) are palmitoylation targets [37]. Dynamic mechanisms for the activity of the palmitoylation enzyme DHHC5 in response to synaptic activity include release from the synapse and translocation to dendritic shafts [38]. Palmitoylation of catenin results in its stabilization in the synapse, and other downstream sequelae of acute synaptic plasticity [39]. Golgi apparatus-localized palmitoyltransferases modulate localization of PI4-kinase IIa, an enzyme which contributes to normal trafficking of endosomes and processes such as phagocytosis [40]. Palmitoylation of the Ndel1 complex, which interacts with dynein to regulate molecular trafficking in neurons, can 'finetune' the activity of this complex (for which impaired function is implicated in several neurodegenerative diseases) [41]. It should be emphasized that palmitoylation effects on molecular or biochemical function are not limited to neuronal phenotypes. DHHC 5/8 contributes to coincident ankyrin-G and BII-spectrin binding to phosphoinositide lipids in an epithelial cell line [42], linking together tissue structure and cell signalling. In lens epithelium, palmitoylation of the integral membrane protein, Aquaporin-0, holds it in detergent-resistant lipid raft domains of the plasma membrane [43]. In addition to synaptic function events, palmitate has been shown to interact directly with (nuclear) histones and presumably have epigenetic functions to contribute to gene transcription regulatory events. Nuclear lipid mediators (e.g., DAG, arachidonic acid, and ceramide [19]) can interact with nuclear signaling enzymes such as the PI3kinase/AKT system, to indirectly modify gene transcription. Specific fatty acids, including palmitic acid, can become covalently attached to histones, allowing for more direct influence on gene transcription $[44,45]$. Lipids are an integral part of the nucleus, present in the nuclear envelope, the nuclear matrix and chromatin, and can contribute to the regulation of gene expression [44,46], a finding reported across many phyla. Palmitate can modulate chromatin directly and indirectly, via physical interaction with telomeres [44]; palmitoylation of histones 3 and 4 [47,48]; and biochemical modulation of histone acetyltransferase [49]. Finally, extracellular (non-transported) palmitate has been shown to increase expression of amyloid precursor protein in the human neuroblastoma cell line SK-N-MC [50], suggesting that palmitate does not need to be transported into the cell to have gene expression effects with significant implications for behavioral function.

Dietary palmitate can alter food reward behaviors. The dopamine re-uptake transporter can be palmitoylated, which contributes to regulation of its trafficking in and out of the plasma membrane, and its activity [51,52]. Since the DAT functions to clear dopamine from the synapse it is not immediately obvious how these cellular biochemical findings fit with the observed behavioral effects of dietary palmitate to increase sucrose reward or other reward behaviors: Figlewicz reported that sub-chronic feeding of diets moderately elevated in palmitic or stearic acid both resulted in significant enhancement of lever-pressing for sucrose solutions by rats [53]. Decarie-Spain [54] reported an increase of compulsive sucrose-seeking in mice fed a diet elevated in palmitate, although this more complex model with a longer diet intervention did manifest frank obesity, thus is not an isolated model of dietary fatty acid effects. In a separate study, this group reported a blunting of behavioral sensitivity to amphetamine, and to exogenous type1 dopamine receptor agonist, along with measurements from the 'reward area' of the brain, the nucleus accumbens, showing decreased DAT protein (which would contribute to elevated synaptic dopamine levels); increased type1 dopamine receptor levels; and increased levels of phosphorylated DARPP32-Thr75, an intracellular signaling mediator that could antagonize D1 post-receptor actions [55]. In this study, mice were fed a diet of $50 \%$ kcal of saturated fat, based on palm oil, but did not become obese. It should be noted that blunted reward perception and dopaminergic function have been reported in rodent models of mixed high fat diet [56], and in obese humans, whereas increased reward function occurs in the weight range of 'overweight' humans and in rodents fed a moderate mixed-fat diet (see [57] for discussion). The variability in diet-obese rodent models and human observations may be ascribed to factors such as exact diet composition, timing and length of exposure to diet, and other variables (such as gender). What is clear is that dopaminergic function, and behavioral sequelae, can be modified by fatty acids in the diet. The mixed results in experimental models also emphasize the gap between knowledge of direct cellular and biochemical fatty acid effects and the behavioral consequences of these fatty acids in the diet. As discussed above, lipidomics profiles in key brain regions in animal models would be a useful first step to clarify local synaptic, and behavioral, events downstream from altered diet. Finally, it is possible, in fact likely, that ingestive or rewarding stimuli trigger changes in S-acylation processes. Van Dolah and colleagues [58] reported that cocaine administration resulted in an increase of palmitoylation of AMPA receptor subunits GluA1 and 3 in striatal neurons and enhanced susceptibility to intracellular internalization. Pharmacologic prevention of this palmitoylation was associated with a maintained sensitivity to the psychomotor effects of cocaine, in rats. The speculative significance of these findings is that there are bi-directional links, if not actual feedback loops, between cellular lipidation events and behavioral outcomes.

Several classes of receptors that play important roles in components of food reward and ingestive behaviors can, and have been reported to be, palmitoylated. It is estimated that more than $70 \%$ of known Gprotein coupled receptors (GPCRs) contain palmitoylation sites and palmitoylation can play a role in intracellular localizations of some GPCRs, which can signal in the absence of ligand, and can even access the nucleus for interaction with chromatin and direct effects on gene transcription [59]. A recent tool for scientists interested in delving further into the importance of protein palmitoylation is the SwissPALM2 website (swisspalm.org) developed by Van Der Goot and colleagues [60], which organizes published information on protein databases from numerous species and cross-references studies on identification of, or potential for, palmitoylation on these proteins. Table 2 provides abridged information for receptors of interest for ingestive or reward behaviors; this list is not exhaustive but provides an example of information available at the website.

Several general considerations need to be considered, with regard to the S-acylation activity of cellular palmitate. Greaves et al [61] emphasize that most reporting of S-acylation events has focused on palmitate; this is in part attributed to availability of experimental techniques that bias observations for palmitate such as measures of ${ }^{3} \mathrm{H}$ palmitate incorporation into proteins. However other common (and dietary) fatty acids have the capacity to form the thioester linkage including stearate, oleate, and palmitoleate, and the authors speculate that incorporation of significant amounts of unsaturated fatty acids (e.g., oleate) may prevent forward transport of a protein from the Golgi apparatus. Since decreased or increased palmitoylation events may both result in protein retention in the Golgi [62], it seems clear that both absolute and relative availability of different fatty acids to the cellular machinery of regulatory protein trafficking can significantly impact cell (neuronal) signaling. Finally, although the S-palmitoylation event is reversible, the time course for removal of palmitate likely varies with the protein target, thus both time and timing of palmitoylation events is likely not 'one size fits all'. While these considerations may add to the complexity of studies evaluating this system as a cellular target for therapeutics, aspects such as the on-off timecourse of specific S-acylation events might be successfully exploited.

Although palmitate clearly contributes to normal synaptic functioning within the CNS, toxic effects and behavioral anomalies, including those tied to ingestive behaviors, have been identified. The 
Table 2

Evaluation of palmitoylation of receptors implicated in ingestion and reward. Adapted and abridged from www.SwissPalm.org *

\begin{tabular}{|c|c|c|c|c|}
\hline RECEPTOR & & PALMITOYL-PROTEOMICS & IDENTIFIED & PREDICTED \\
\hline Orexin & & & & yes \\
\hline Ghrelin & mouse, human & 0 & 0 & no \\
\hline DR1 & human & & & yes \\
\hline DR2 & human & & & yes \\
\hline MC4R & rat, mouse, human & 0 & 0 & yes \\
\hline GBR-A1 & rat, mouse, human & 0 & 0 & no \\
\hline GBR-A2 & rat, human & 0 & 0 & no \\
\hline GBR-B1 & rat, mouse, human & 0 & 0 & yes \\
\hline GBR-B2 & rat, human & 0 & 0 & yes \\
\hline B2 & mouse & 1 & 0 & yes \\
\hline \multirow[t]{3}{*}{ CBR-1 } & rat & 1 & 0 & yes \\
\hline & mouse & 2 & 2 & yes \\
\hline & human & 0 & 1 & yes \\
\hline \multirow[t]{2}{*}{ CBR-2 } & rat, mouse & 0 & 0 & no \\
\hline & human & 0 & 0 & yes \\
\hline \multirow{3}{*}{ MOR } & rat & 0 & 1 & no \\
\hline & mouse & 1 & 1 & yes \\
\hline & human & 0 & 0 & yes \\
\hline \multirow{2}{*}{$5 \mathrm{HT2a}$} & mouse & 1 & 1 & yes \\
\hline & rat, human & 0 & 0 & yes \\
\hline SERT & rat & 1 & 0 & yes \\
\hline \multirow[t]{2}{*}{ 5HT1a } & rat, human & 0 & 0 & yes \\
\hline & mouse & 0 & 2 & yes \\
\hline $5 \mathrm{HT} 2 \mathrm{c}$ & rat, human & 0 & 0 & yes \\
\hline
\end{tabular}

* Blanks represent 'no reported tests'; "identified" represent tests using mass spectroscopy or site-directed mutagenesis.

potential harm of accumulation of palmitoylated proteins is shown by the human neuronal degenerative disease, neuronal ceroid lipofuscinosis, and in hippocampus from a mouse model which has knock-out of palmitoyl-protein thioesterase 1 (PPT1) [63]. Perhaps not surprisingly, the rate of depalmitoylation of specific synaptic proteins differs (for example PSD-95 vs. glutamate receptor subunits [64]); this may be a useful functional target for modulation of palmitoylation events. Palmitate treatment of SHSY5Y neuroblastoma cells in vitro, and mouse hippocampus in vivo, results in activation of the transcription factor CHOP (C/EBP Homologous Protein) and increased endoplasmic reticulum (ER) stress [65]. In a mouse model, age-related increases of a number of palmitoylated proteins in the frontal cortex were associated with impairment of executive function and reference memory [66].

Important for ingestive behaviors, palmitate has been shown to induce neuroinflammatory responses within the nucleus accumbens [54] and hypothalamus (see Tran 2016 for review [67]), resulting in altered feeding behavior and energy homeostasis. Mice fed a saturated-fat diet manifested with anxiety-like behavior, compulsive sucrose seeking, and pro-inflammatory changes in the nucleus accumbens, including increased expression of IKKB, IL-1B, and Iba-1, together with reactive gliosis [54]. Research from the labs of Benoit [68] and Belsham [69] demonstrated in vivo, and in vitro in cultured hypothalamic neurons, that exposure to palmitate generates a state of insulin resistance characterized by changes in major cell signal pathways. In addition to potential direct neuronal effects of palmitate on hypothalamic neurons (and downstream, on energy homeostasis), it is now appreciated that dietary fat, including dietary palmitic acid, alters microglial function and contributes to a pro-inflammatory profile (see [70,71] for detailed review and discussion of crosstalk between microglia and astrocytes with neurons). Importantly, the generation of inflammatory markers occurs relatively rapidly, and independent of obesity, in models of highfat diet feeding. Following a report of a hypothalamic pro-inflammatory response to high fat diet in mice [72], a key study from Milanski and colleagues [73] demonstrated enhanced Toll-like receptor 4 expression in microglia concomitant with intake of a high fat diet; and they reported differential expression of inflammatory markers based upon intracerebroventricular fatty acid infusions. Thus, oleic acid infusion resulted in expression of anti-inflammatory IL- 6 and IL-10, whereas infusion of a saturated animal fatty acid mixture, which included palmitic and stearic acids, resulted in expression of TNFa, IL1-B, and IL-6. Comparable findings came from Posey et al [12], who reported increased hypothalamic phosphorylated-IKKB in rats fed a high fat diet, or receiving intracerebroventricular infusion of palmitate for $6 \mathrm{hr}$. Likewise, pro-inflammatory proteins (TNF- $\alpha$, IL1- $\beta$, IL- 6 and pIкBa) were increased in mediobasal and paraventricular hypothalamic nuclei of mice infused intracerebroventricularly with palmitate [74]. The unique involvement of microglia in hypothalamic inflammation following saturated fat (including palmitate) intake was supported by studies whereby cultured mouse microglia, but not astrocytes, become activated following exposure to saturated fatty acids [75]. Prevention of the increase or signaling of microglia in mouse models was effective in decreasing food intake and increased adiposity [76, 77]. Cultured microglia increase expression of the receptor for orexin, a neuroprotective peptide transmitter in the CNS [78] and manifest a pro-inflammatory response profile, following incubation with palmitate; and pre-treatment with orexin turned down the pro-inflammatory response and decreased microglial cell death. Thus, cellular mechanisms appear to be in place to modulate the toxic and dyshomeostatic effects of palmitate in the hypothalamus and these mechanisms might be overwhelmed with chronic high-level exposure. Intriguingly, Fatty Acid Binding Protein 4 has been implicated in both isolated microglia, and hypothalamic tissue, as a mediator of the neuroinflammatory response [79]. This finding warrants further investigation into the roles of specific fatty acid binding proteins/transporters (or their absence) in the expression of a neuroinflammatory response that is clearly tied to energy dyshomeostasis.

\section{OTHER FATTY ACIDS}

As alluded to above, the fatty acid oleate (oleic acid) appears to have actions that antagonize, reverse, or prevent palmitate effects whether examined behaviorally, or at synaptic or cellular levels. Potential direct effects of oleate are supported by patch-clamp recording studies from individual hypothalamic neurons which reveal distinctive responsivity to the monounsaturated fatty acid oleic acid (OL) [80]. In vivo studies have demonstrated that OL injected into the 
third ventricle close to the medial hypothalamus can result in decreased food intake and glucose production [81], and activation of hypothalamic $\mathrm{K}_{\mathrm{ATP}}$ channels appear to be a cellular intermediate for this effect. More recently, Hryhorczuk and colleagues [82] reported that oleic acid infused into the ventral tegmental area (the nucleus for dopaminergic cell bodies) could decrease overall food intake; food reward behavior (operant responding for a highly palatable food); and dopaminergic neuronal activity assessed using whole-cell current-clamp recordings of spontaneous electrical activity. Tse and Belsham [83] evaluated palmitate effects on a number of cell signals and proinflammatory and endoplasmic reticulum stress markers, in an immortalized hypothalamic cell line of POMC neurons. These are one major class of energy homeostasis-regulating neuron in the hypothalamus. Palmitate-induced increases of Pomc, CHOP, and IL-6 could be reversed by including oleate in the medium, suggesting some interacting (and antagonistic) mechanisms of action for these two fatty acids, which might be evaluated in other cell systems (microglia) or behavioral paradigms. As one example, Guzman and colleagues [84] reported a protective effect of oleic acid in vivo to counter oxidative stress responses in the rat brain, which were secondary to the administration of the anti-cancer agents, cyarabine and doxorubicin.

Biochemical and synaptic effects of the fatty acid stearate have been reported although findings have not been as extensive as those for dietary palmitate. As reported for palmitate, stearoylation of nuclear Histone 3 variants can also occur (see [47] for detailed information regarding mammalian protein targets for fatty acylation). And in keeping with reports of both specificity for acyl type and for protein target, S-acylation of hemagglutinin has specificity for location of palmitate vs. stearate regions of attachment [85]. Stearate has been identified as a signaling molecule that maintains normal mitochondrial function, binding to the transferrin receptor [86]. Finally, recent reports of a new class of endogenous lipids with anti-inflammatory effects, including palmitic acid hydroxystearic acids (PAHSAs) provide rationale for further study of the identification, processing, and function of these modified fatty acids in the CNS (see [87] for discussion and references).

In addition to (dietary) saturated fatty acids, polyunsaturated fatty acids (PUFAs) play a significant role in CNS structure, function and signaling. These include (dietary) linoleic and $\alpha$-linolenic acids, which are precursors for arachidonic, and docosahexaenoic (DHA) acids. Detailed discussion of the regulated metabolism and conversion of these main PUFAs into signaling mediators is beyond the scope of this review (see [16] for detailed discussion), but it is noteworthy to point out that a key metabolizing enzyme, phospholipaseA2, which releases fatty acids from phospholipids, is coupled to activation of numerous neurotransmitter receptors. This raises the intriguing possibility of co-activity of fatty acids such as PUFAs along with that of a conventional neurotransmitter, and the modulation of neurotransmitter effects. Following release, PUFAs can then be converted to modified fatty acid moieties. Delineating the positive or harmful attributes of specific PUFA products may have substantive therapeutic value. In terms of normal CNS function, PUFAs are implicated in cognitive function and mood (see [88] for review and discussion), with evidence coming from in vivo and in vitro studies. Important for ingestive and reward-related behaviors, PUFAs are the precursors for endocannabinoids, and can modulate the endocannabinoid system (see discussion below). In a Xenopus laevis model, application of DHA and other PUFAs resulted in opening of neuronal M-channels, an action not mimicked by oleic acid, and implicated in decreased neuronal excitability [89]. Dietary n3-PUFAs enhanced learning and memory function in the SAMP8 mouse strain, and specifically enriched DHA content of phosphatidyl choline, phosphatidyl serine, and phosphatidyl ethanolamine in the hippocampus and amygdala [90]. Dietary DHA and eicosapentanoic acid (EPA) enhanced memory function, hippocampal synaptic transmission, and dendritic morphology in rats experiencing a chronic restraint stress paradigm [91]. Anxiety response to a social defeat paradigm was enhanced in mice fed diets deficient in N-3 fatty acids [92]. Uniquely modified PUFAs can be generated as part of an injury or inflammatory response. Omega-3 PUFAs can attenuate microglial inflammatory responses in vitro [93] and in vivo [94] in a mouse traumatic brain injury model. Given the role of microglia and the inflammatory response in high fat diet-induced energy dyshomeostasis, the prophylactic or attenuating role of dietary PUFAs seems obvious. In fact, linoleic acid had a direct antagonistic effect on stearic acid effects on expression of inflammatory compounds and the orexigenic peptide AgRP, in a mouse hypothalamic cell line [95].

\section{EFFECTS OF FATTY ACIDS THROUGH ENDOCANNABINOID SIGNALING}

Strictly speaking, the term endocannabinoid refers to a limited (currently nine) number of signaling molecules which are derived from long chain (C18 or longer) polyunsaturated fatty acids (LCPUFAs) and display significant affinity for the cannabinoid receptors $\mathrm{CB}_{1}$ and $\mathrm{CB}_{2}$ $[96,97]$. In the late 1980's, these G-protein coupled receptors (GPCRs) were found to be responsible for the binding and effects of (-)-trans- $\Delta 9$ tetrahydrocannabinol $(\Delta 9-\mathrm{THC})$, the main psychoactive compound present in the Cannabis plant $[98,99]$. Of the two cannabinoid receptors, $\mathrm{CB}_{1}$ is by far the most important for energy homeostasis and appetite regulation $[100,101]$. This receptor is abundantly present in brain [102-104], as well as outside the CNS [105]. Originally it was assumed that $\mathrm{CB}_{1}$ receptors are mainly pre-synaptically located at nerve terminals, acting as modulators of synaptic transmission by a process called retrograde signalling [106,107]. This mechanism implies that neuronal depolarization causes cleavage of membrane lipid precursors to induce de novo synthesis and release of endocannabinoids and structurally related fatty acid-derived signalling molecules into the synaptic cleft. These molecules in turn activate $\mathrm{CB}_{1}$ and (or) other receptors located on presynaptic terminals of neurons, which reduces release of neurotransmitters (such as GABA or glutamate) onto the postsynaptic neuron. Endogenously released cannabinoids might also act via TRP ligand gated ion channels (e.g. TPRV1) and other GPCRs (e.g. GPR 55). The endocannabinoids are taken back up into neuronal and glial cells and then degraded by enzymes such as fatty acid amide hydrolase (FAAH) and MAG-lipase (MAGL) (see [107] for recent review). However, it has become clear that $\mathrm{CB}_{1}$ receptors are also among the ever-growing list of GPCRs that are also located intracellularly. Studies have demonstrated functional $\mathrm{CB}_{1}$ receptors associated with endosomes/lysosomes [108] and mitochondria [109-112]. In brain, about $30 \%$ of the total $\mathrm{CB}_{1}$ population was found to be located in the outer mitochondrial membrane of brain neuronal cells and astrocytes [109,110,112-114]. Apparently, these mitochondrial $\mathrm{CB}_{1}$ receptors $\left(\mathrm{mtCB}_{1}\right)$ are involved in the regulation of cellular respiration and energy production, as endocannabinoids were found to suppress electron transport complex I activity and respiration in isolated mitochondria, probably by reducing cAMP levels and PKA activity [113]. Interestingly, $\mathrm{mtCB}_{1}$ receptors are not restricted to the CNS, as recent studies have shown their presence also in muscle cells [115] and in renal proximal tubular cells, where they are also involved in the regulation of mitochondrial functioning [116]. With respect to nervous tissue, it has been suggested that $\mathrm{mtCB}_{1}$ play important roles in the modulation of synaptic transmission, neuronal homeostasis and apoptosis, the production of reactive oxygen species, and metabolism of neurotransmitters [109].

Since the discovery of the first two endogenous ligands of cannabinoid receptors, anandamide ( $\mathrm{N}$-arachidonoylethanolamine, AEA) and 2 -arachidonoylglycerol (2-AG), it has become clear that these prototypical endocannabinoids are members of a much larger class of structurally related amides, esters and ethers, all derived from fatty acids. These molecules exist in a continuous dynamic equilibrium with each other, their fatty acid precursors and several of their metabolites [11,117]. Among them, the fatty (acid-) amides (Lipid Maps class FA08; 
http://www.lipidmaps.org), to which anandamide (AEA) also belongs, are the most diverse and abundantly present class. Most, if not all, fatty acid amides found in vivo are conjugates of medium-long chain fatty acids with amines, including ethanolamine, neurotransmitters (serotonin, dopamine) or simple amino acids. Their synthesis takes place via different multi-step processes which are partly operating in parallel $[11,118]$. They appear to be involved in various regulatory processes, although for some of these compounds no biological role has been discovered yet. In animals, their molecular targets go far beyond $\mathrm{CB}_{1}$ and $\mathrm{CB}_{2}$, and include a wide range of other receptors, including GPR55, GPR18, GPR119, TRPA1 (transient receptor potential ankyrin 1), TRPV1 (transient receptor potential channel type V1), PPARs (peroxisome proliferator activated receptors) as well as several non-receptor targets $[11,107]$. Next to the fatty acid amides, ester analogues of 2-AG, including 2-oleoylglycerol and 2-linoleoylglycerol are receiving increasing interest because of their involvement in food-intake and appetite regulation [11]. The highly versatile and complex roles of fatty acid amides and esters are also reflected by the finding that some (if not all) of the 'true' endocannabinoids themselves display 'promiscuous' behaviour as the can activate or block other receptors besides $\mathrm{CB}_{1}$ or $\mathrm{CB}_{2}$, sometimes with potencies that differ little from those with which they interact with cannabinoid receptors. Biochemical pathways for synthesis and degradation of endocannabinoids and their congeners show several crossroads with those of other lipid mediators, including eicosanoids. This not only creates a versatile biochemical network with regulatory nodes, but also leads to the formation of 'hybrid' structures, including prostamides and other oxidation products, which can possess bio-activity [117]. Taken together, an 'expanded' view of the endocannabinoid system (ECS) is now considered the best way to comprehend this group of signalling molecules, their receptors and enzymes involved in their synthesis and breakdown [107,119].

It has also become clear that the complexity of the ECS and its pleiotropic roles provide major scientific challenges to understand its biology let alone to be able to selectively interfere with it. In hindsight, this complexity has also been the main cause for the therapeutic failure of the $\mathrm{CB}_{1}$ 'blockers' (antagonists and reverse agonists) as therapeutic class, around 2006. Initially, the discovery of the $\mathrm{CB}_{1}$ receptor and its prominent role in food-intake generated enormous research activity in the field, and expectations were high to develop a completely new class of drugs for weight management. Indeed, preclinical and early clinical studies with $\mathrm{CB}_{1}$ blockers showed spectacular effects on food intake. However, around 2007 developments took a dramatic turn when rimonabant and several other candidate drugs failed because of their severe side-effects in humans. Clearly, these events caused a major setback in endocannabinoid research related to appetite regulation and food-intake. At the same time, there has never been any scientific doubt about the importance of endocannabinoids and their congeners for both homeostatic and hedonic eating. Much attention is given to the involvement of $\mathrm{CB}_{1}$ and other receptors, as well as their ligands in the rewarding effects of food [11,120-122]. From a neurological perspective it is clear that mechanisms involved are very complex. For example, studies suggest that $\mathrm{CB}_{1}$ activation in brain does not simply lead to orexigenic (appetite-inducing) responses, but that location of receptors can make a difference [123]. Within the brain, the ECS links to different endocrine and neuronal pathways, including dopaminergic circuits in the mesocorticolimbic system such as the ventral tegmental area and the nucleus accumbens (NAc), which are crucial for hedonic eating [11]. Similarly, links were demonstrated between endocannabinoid and opioid neurotransmission within a dorsomedial NAc shell hedonic hotspot [124]. Earlier studies of Kirkham et al. [125] already showed in rats that 24 hours of food restriction resulted in increased levels of AEA and 2-AG in the limbic forebrain, and to a lesser extent of 2-AG in the hypothalamus. In the same study it was found that injection of 2-AG into the NAc shell caused a dose-dependent increase of food-intake, which was attenuated in animals that had been pretreated by s.c. injection with the $\mathrm{CB}_{1}$ inverse agonist rimonabant
(SR141716). Also in the hypothalamus, the ECS cross-links with different circuits involved in eating behaviour. For example, within the ARC, the ECS modulates activity of AgRP/NPY [126] and POMC [112] neurons. Furthermore, endocannabinoid signalling interacts with metabolic hormones including leptin, ghrelin and insulin [127-129]. Another possible level of interaction of the ECS with eating behaviour can take place via the central processing of food sensations such as olfactory or gustatory signals. For example, in the $\mathrm{PBN}, \mathrm{CB}_{1}$ receptors were found to gate the gustatory neurotransmission associated with palatable foods. Their activation increased consumption of palatable foods, but not of a standard diet [130]. In line with this, fasted mice were found to display $\mathrm{CB}_{1}$-dependent increased odour detection in the olfactory bulb [131]. In the GI tract, $\mathrm{CB}_{1}$ receptors are found on nerve fibres, with the highest density in the two ganglionic plexuses, the myenteric and submucosal plexus, of the enteric nervous system. They are involved in the release of satiety hormones by entero-endocrine cells [132]. Other receptors, including GPR119, PPARs and Transient receptor potential (TRP) cation channels that bind endocannabinoid congeners like oleoylethanolamine (OEA) and 2-oleolylglycerol (2-OG) play a role in satiety [11]. Several studies have shown correlations between fatty acid composition of the diet consumed over a certain period of time (days weeks) and endocannabinoid patterns in peripheral tissues [133] and in brain [134]. Interestingly, these effects go far beyond the typical $\mathrm{CB}_{1}$ ligands like anandamide (AEA) and 2-AG, and include for example conjugates of DHA, oleic acid and palmitic acid. Given their different relative affinities for the $\mathrm{CB}_{1}$ and other receptors, it is conceivable that this may have biological consequences within and outside the CNS. However, even in experimental animals it is extremely difficult to disentangle these effects in the CNS as they are likely to be region-specific. For humans, there is some information from studies using positron emission tomography $[135,136]$. For example, Ceccarini and colleagues used the $\mathrm{CB}_{1}$ radioligand [18F]MK-947030 to measure $\mathrm{CB}_{1}$ availability in 54 patients with different food intake disorders, having a wide range $\left(12.5-40.6 \mathrm{~kg} / \mathrm{m}^{2}\right)$ of body mass indices (BMI) [137]. The authors found that $\mathrm{CB}_{1}$ availability was inversely associated with BMI in homeostatic brain regions such as the hypothalamus and brainstem areas in both patients with anorexia nervosa, bulimia nervosa, or functional dyspepsia and healthy subjects. Interestingly, in persons with food intake disorders, $\mathrm{CB}_{1}$ availability was also negatively correlated with BMI throughout the mesolimbic reward system, pointing towards an association between the ECS and reward systems in this group.

To summarize, the diversity of ECS compounds, their actions, and interactions with other energy homeostasis pathways and mediators, make them unlikely candidates, at this time, for utility as stand-alone pharmacotherapeutic agents for body weight management. Conversely, a better understanding of the ECS in relation to hedonic effects of specific foods and diets can contribute to developing new strategies to optimise the balance between energy and nutrient intake. This can be of relevance for specific target groups, not only the obese and overweight, but potentially also individuals suffering from malnutrition. Examples of the latter include persons with disease-related anorexia, as well as older persons suffering from persistent loss of food enjoyment and appetite resulting in malnutrition and involuntary weight loss [121].

\section{CONCLUSION}

In conclusion, elucidation of signaling effects of common dietary fatty acids is a frontier for ingestive behaviors research. It should be clear that there are multiple potential effects of fatty acids, from the synapse into the cell nucleus, and that testing the relevance of some of these effects, or their downstream sequelae, may be useful for the deeper understanding of ingestive behavior processes, both homeostatic and hedonic. There is a great deal of information that could be systematically collected: lipidomics to link dietary intake with brain lipidomic profiles, for identifying key 'nutritional targets' in the circuitry; clarification of target CNS phenotypes (a great deal more could be 
known about fatty acid effects on neurons, glia, and astrocytes); and delineation of intracellular processes, which will be specific for brain region and cell phenotype. Fortunately, tools for these determinations, and the validation of their importance to ingestive behaviors, are available based upon studies in other cell systems. The 'next generation' of research into signaling effects of fatty acids may synthesize pieces of information that have been collected in disparate systems, and point towards novel cell signaling targets for pharmacotherapeutic approaches tailored for dysfunctional ingestive behaviors.

\section{ACKNOWLEDGMENTS}

Dianne Figlewicz Lattemann is a Health Research Scientist, Department of Veterans Affairs Puget Sound Health Care System, Seattle, Washington and is supported by Merit Review Award 1 I01 BX004231-01A1, Biomedical Laboratory Research and Development Service. We thank Drs. Ernie Blevins and Bill Banks for helpful discussion. Data for Figure 2 was supported by NIH DK-40963 (DFL), and the Mouse Metabolic Phenotype Core, University of Cincinnati, Grant U2C DK059630 (Dr. Patrick Tso). Additional support comes from Department of Veterans Affairs VISN 20 Northwest Network Mental Illness Research, Education, and Clinical Center (MIRECC).

\section{REFERENCES}

[1] CM Duffy, JJ Hofmeister, JP Nixon, TA Butterick, High fat diet increases cognitive decline and neuroinflammation in a model of orexin loss, Neurobiol Learn Mem 157 (2019) 41-47.

[2] C Boitard, A Cavaroc, J Sauvant, A Aubert, N Castanon, S Laye, G Ferreira, Impairment of hippocampal-dependent memory induced by juvenile high-fat diet intake is associated with enhanced hippocampal inflammation in rats, Brain Behav Immun 40 (2014) 9-17.

[3] SJ Gainey, KA Kwakwa, JK Bray, MM Pillote, VL Tir, AE Towers, GG Freund, Short-term high-fat diet (HFD) induced anxiety-like behaviors and cognitive impairment are improved with treatment by glyburide, Front Behav Neurosci 10 (2016) 156.

[4] C Boitard, SL Parkes, A Cavaroc, F Tantot, N Castanon, S Laye, S Tronel, G Pacheco-Lopez, E Coutureau, G Ferreira, Switching adolescent high-fat diet to adult control diet restores neurocognitive alterations, Front Behav Neurosci 10 (2016) 225.

[5] DP Figlewicz, JL Bennett, AM Naleid, C C Davis, JW Grimm, Intraventricular insulin and leptin decrease sucrose self-administration in rats, Physiol Behav 89 (2006) 611-616.

[6] AC Reichelt, MJ Morris, RF Westbrook, Cafeteria diet impairs expression of sensory-specific satiety and stimulus-outcome learning, Front Psychol 5 (2014) 852.

[7] F Naneix, F Tantot, C Giangetas, J Kaufling, Y Janthakhin, C Coitard, V De SmedtPeyrusse, JR Pape, S Vancassel, P Trifilieff, F Georges, E Coutureau, G Ferreira, Impact of early consumption of high-fat diet on the mesolimbic dopaminergic system, eNeuro 4 (3) (2017) e0120-17.2017.

[8] MG Baladi, W Koek, M Aumann, F Velasco, CP France, Eating high fat chow enhances the locomotor-stimulating effects of cocaine in adolescent and adult female rats, Psychopharmacol 222 (2012) 447-457.

[9] MG Baladi, RE Horton, WA Owens, LC Daws, CP France, Eating high fat chow decreases dopamine clearance in adolescent and adult male rats but selectively enhances the locomotor stimulating effects of cocaine in adolescents, Int $\mathrm{J}$ Neuropsychopharm 18 (7) (2015) 1-11.

[10] BA McGuire, MG Baladi, CP France, Eating high-fat chow enhances sensitization to the effects of methamphetamine on locomotion in rats, Eur J Pharmacol 658 (2011) 156-159.

[11] RF. Witkamp, The role of fatty acids and their endocannabinoid-like derivatives in the molecular regulation of appetite, Mol Aspects Med 64 (2018) 45-67.

[12] KA Posey, DJ Clegg, RL Printz, J Byun, GJ Morton, A Vivekanandan-Giri, S Pennathur, DG Baskin, JW Heinecke, SC Woods, MW Schwartz, KD Niswender, Hypothalamic proinflammatory lipid accumulation, inflammation, and insulin resistance in rats fed a high-fat diet, Am J Physiol Endocrinol Metab 296 (2009) E1003-E1012.

[13] MF Fernandes, MC Tache, SL Klingel, F Leri, Safflower (n-6) and flaxseed (n-3) high-fat diets differentially regulate hypothalamic fatty acid profiles, gene expression, and insulin signaling, Prostaglandins, Leukotrienes and Essential Fatty Acids 128 (2018) 67-73.

[14] WA Banks, AJ Kastin, SI Rapoport, Permeability of the blood-brain barrier to circulating free fatty acids, in: S Yehuda, DI Mostofsky (Eds.), Handbook of Essential Fatty Acid Biology: Biochemistry, Physiology, and Behavioral Neurobiology, Humana Press, Totowa, New Jersey, 1997.

[15] JA Hamilton, K. Brunaldi, A model for fatty acid transport into the brain, J Mol Neurosci 33 (2007) 12-17.

[16] R Bazinet, S. Laye, Polyunsaturated fatty acids and their metabolites in brain function and disease, Nature Reviews|Neuroscience 18 (2014) 771-785.
[17] Y Ochiai, Y Uchida, S Ohtsuki, M Tachikawa, S Aizawa, T Terasaki, The bloodbrain barrier fatty acid transport protein 1 (FATP1/SLC27A1) supplies docosahexaenoic acid to the brain, and insulin facilitates transport, J Neurochem 141 (2017) 400-412.

[18] EJ. Murphy, The blood-brain barrier and protein-mediated fatty acid uptake: role of the blood-brain barrier as a metabolic barrier, J Neurochem 141 (2017) 324-329.

[19] M Garcia-Gil, E. Albi, Nuclear lipids in the nervous system: what they do in health and disease, Neurochem Res 42 (2017) 321-336.

[20] Y Oomura, T Nakamura, M Sugimori, Y Yamada, Effect of free fatty acid on the rat lateral hypothalamic neurons, Physiol Behav 14 (1975) 483-486.

[21] RH Eckel, RJ. Robbins, Lipoprotein lipase is produced, regulated, and functional in rat brain, Proc Natl Acad Sci U S A 81 (23) (1984) 7604-7607.

[22] C LeFoll, AA Dunn-Meynell, S Musatov, C Magnan, BE Levin, FAT/CD36: a major regulator of neuronal fatty acid sensing and energy homeostasis in rats and mice, Diabetes 62 (2013) 2709-2716.

[23] C Salaun, J Greaves, LH Chamberlain, The intracellular dynamic of protein palmitoylation, J Cell Biol 191 (2011) 1229-1238.

[24] LH Chamberlain, MJ. Shipston, The physiology of protein S-acylation, Physiol Rev 95 (2015) 341-376.

[25] AK Globa, SX. Bamji, Protein palmitoylation in the development and plasticity of neuronal connections, Curr Opin Neurobiol 45 (2017) 210-220.

[26] Y Fukata, T Murakami, N Yokoi, M Fukata, Local palmitoylation cycles and specialized membrane domain organization, Curr Topics Membranes 77 (2017) 97-141.

[27] D Indranil, S. Sadhukhan, Emerging roles of DHHC-mediated protein S-palmitoylation in physiological and pathophysiological context, Eur J Cell Biol 97 (2018) 319-338.

[28] R Bhattacharyya, C Barren, DM Kovacs, Palmitoylation of amyloid precursor protein regulates amyloidogenic processing in lipid rafts, J Neurosci 33 (2013) 11169-11183.

[29] KS Vetrivel, X Meckler, Y Chen, PD Nguyen, NG Seidah, R Vassar, PC Wong, M Fukata, MZ Kounnas, G Thinakaran, Alzheimer disease Abeta production in the absence of S-palmitoylation-dependent targeting of BACE1 to lipid rafts, J Biol Chem 284 (2009) 3793-3803.

[30] RJ Andrew, CG Fernandez, M Stanley, H Jiang, P Nguyen, RC Rice, V BuggiaPrévot, P De Rossi, KS Vetrivel, R Lamb, A Argemi, ES Allaert, EM Rathbun, SV Krause, SL Wagner, AT Parent, DM Holtzman, G Thinakaran, Lack of BACE1 Spalmitoylation reduces amyloid burden and mitigates memory deficits in transgenic mouse models of Alzheimer's disease, Proc Natl Acad Sci U S A 114 (45) (2017) E9665-E9674.

[31] J Greaves, KR Munro, SC Davidson, M Riviere, J Wojno, TK Smith, NCO Tomkinson, LH Chamberlain. Molecular basis of fatty acid selectivity in the zDHHC family of S-acyltransferases revealed by click chemistry. PNAS online: E1365-E1374, 2017.

[32] K Huang, S Sanders, R Singaraja, P Orban, T Cijsouw, P Arstikaitis, A Yanai, MR Hayden, A El-Husseini, Neuronal palmitoyl acyl transferases exhibit distinct substrate specificity, FASEB J 23 (2009) 2605-2615.

[33] R Kang, J Wan, P Arstikaitis, H Takahashi, K Huang, AO Bailey, JX Thompson, AF Roth, RC Drisdel, R Mastro, WN Green, JR Yates III, NG Davis, A El-Husseinie, Neural palmitoyl-proteomics reveals dynamic synaptic palmitoylation, Nature 456 (2008) 904-909.

[34] S Oddi, TM Stepniewski, A Totaro, J Selent, L Scipioni, B Dufrusine, F Fezza, E Dainese, M Maccarrone, Palmitoylation of cysteine 415 of $\mathrm{CB}_{1}$ receptor affects ligand-stimulated internalization and selective interaction with membrane cholesterol and caveolin 1, Biochim Biophys Acta 1862 (2017) 523-532.

[35] C Salaun, L Ritchie, J Greaves, TJ Bushell, LH Chamberlain, The C-terminal domain of zDHHC2 contains distinct sorting signals that regulate intracellular localization in neurons and neuroendocrine cells, Mol Cell Neurosci 85 (2017) 235-246.

[36] JJ Shimmell, BS Shah, SM Cain, S Thouta, N Kuhlmann, I Tatarnikov, DB Jovellar, GS Brigidi, J Kass, AJ Milnerwood, TP Snutch, SX Bamji, The X-linked intellectual disability gene $Z d h h c 9$ is essential for dendrite outgrowth and inhibitory synapse formation, Cell Reports 29 (2019) 2422-2437.

[37] GR Prescott, OA Gorleku, J Greaves, LH Chamberlain, Palmitoylation of the synaptic vesicle fusion machinery, J Neurochem 110 (4) (2009) 1135-1149.

[38] GS Brigidi, B Santyr, J Shimell, B Jovellar, SX Bamji, Activity-regulated trafficking of the palmitoyl-acyl transferase DHHC5, Nature Communications 6 (2015) 8200.

[39] GS Brigidi, Y Sun, D Beccano-Kelly, K Pitman, M Mobasser, SL Borgland, AJ Milnerwood, SX Bamji, Palmitoylation of $\delta$-catenin by DHHC5 mediates activity-induced synapse plasticity, Nat Neurosci 17 (2014) 522-532.

[40] D Lu, Sun H-q, B Barylko, Y Fukata, M Fukata, JP Albanesi, HL Yin, Phosphatidylinositol 4-kinase II $\alpha$ is palmitoylated by Golgi-localized palmitoyl transferases in cholesterol-dependent manner, J Biol Chem 287 (2012) 21856-21865.

[41] A Shmueli, M Segal, T Sapir, R Tsutsumi, J Noritake, A Bar, S Sapoznik, Y Fukata, I Orr, M Fukata, O Reiner, Ndel1 palmitoylation: a new mean to regulate cytoplasmic dynein activity, EMBO J 29 (2010) 107-119.

[42] M Ho, KM Abdi, V Bennett, Ankyrin-G palmitoylation and BII-spectrin binding to phosphoinositide lipids drive lateral membrane assembly, J Cell Biol 206 (2014) 273-288.

[43] KL Schey, DB Gutierrez, Z Wang, J Wei, AC Grey, Novel fatty acid acylation of lens integral membrane protein Aquaporin-0, Biochemistry 49 (2010) 1-17.

[44] S Park, EE Patterson, J Cobb, A Audhya, MR Gartenberg, CA Fox, Palmitoylation controls the dynamics of budding-yeast heterochromatin via the telomere-binding protein Rif1, Proc Natl Acad Sci 108 (2011) 14572-14577. 
[45] BR Sabari, D Zhang, C David Allis, Y Zhao, Metabolic regulation of gene expression through histone acylations, Nat Rev Mol Cell Biol 18 (2017) 90-101.

[46] PB. Gahan, Histochemical evidence for the presence of lipid on the chromosomes of animal cells, Exp Cell Res 39 (1965) 136-144.

[47] JP Wilson, AS Raghavan, Y-Y Yang, G Charron, HC Hang, Proteomic analysis of fatty-acylated proteins in mammalian cells with chemical reporters reveals Sacylation of histone H3 variants, Mol Cell 10 (2011) 1-16, https://doi.org/10. 1074/mcp.M110.001198.

[48] C Zou, BM Ellis, RM Smith, BB Chen, Y Zhao, RK Mallampalli, AcylCoA:lysophosphatidylcholine acyltransferase I (Lpcat1) catalyzes histone protein O-palmitoylation to regulate mRNA synthesis, J Biol Chem 286 (2011) 28019-28025.

[49] DC Montgomery, AW Sorum, L Guasch, MC Nicklaus, JL Meier, Metabolic regulation of histone acetyltransferases by endogenous Acyl-CoA cofactors, Chem Biol 22 (2015) 1030-1039.

[50] JY Kim, HJ Le, S-J Lee, YH Jung, DY Yoo, IK Hwang, JK Seong, JM Ryu, HJ Han, Palmitic acid-BSA enhances amyloid-B production through GPR40-mediated dual pathways in neuronal cells: Involvement of the Akt/mTOR/HIF-1 $\alpha$ and Akt/NF-KB pathways, Sci Rep 7 (2017) 4335.

[51] DE Bolland, AE Moritz, DJ Stanislowski, RA Vaughan, JD Foster, Palmitoylation by multiple DHHC enzymes enhances dopamine transporter function and stability, ACS Chem Neurosci 10 (2019) 2707-2717.

[52] JD Foster, RA. Vaughan, Palmitoylation controls dopamine transporter kinetics, degradation, and Protein Kinase C-dependent regulation, J Biol Chem 286 (2011) 5175-5186.

[53] DP Figlewicz, J Jay, CH West, A Zavosh, CS Hampe, JR Radtke, MA Raskind, ER Peskind, Effect of dietary palmitic and stearic acids on sucrose motivation and hypothalamic and striatal cell signals in the rat, Am J Physiol 314 (2018) R191-R200.

[54] L Decarie-Spain, S Sharma, C Hryhorczuk, V Issa-Garcia, PA Barker, N Arbour, $\mathrm{T}$ Alquier, S Fulton, Nucleus accumbens inflammation mediates anxiodepressive behavior and compulsive sucrose seeking elicited by saturated dietary fat, Mol Metab 10 (2018) 1-13.

[55] C Hryhorczuk, M Florea, D Rodaros, I Poirier, C Daneault, C Des Rosiers, A Arvanitogiannis, T Alquier, S Fulton, Dampened mesolimbic dopamine function and signaling by saturated but not monounsaturated dietary lipids, Neuropsychopharmacol 41 (2016) 811-821.

[56] JF Davis, AL Tracy, JD Schurdak, MH Tschöp, JW Lipton, DJ Clegg, SC Benoit, Exposure to elevated levels of dietary fat attenuates psychostimulant reward and mesolimbic dopamine turnover in the rat, Behav Neurosci 122 (2008) 1257-1263.

[57] DP. Figlewicz, Modulation of food reward by endocrine and environmental factors: update and perspective, Psychosomatic Medicine 77 (2015) 664-670.

[58] DK Van Dolah, L-M Mao, C Shaffer, M-L Guo, EE Fibuch, X-P Chu, S Buch, JQ Wang, Reversible palmitoylation regulates surface stability of AMPA receptors in the nucleus accumbens in response to cocaine in vivo, Biol Psychiatry 69 (2011) 1035-1042.

[59] B. Chini, Expanding neuropeptide signaling by multiplying receptor functional states and sub-cellular locations, Cell Tissue Res 375 (2019) 49-56.

[60] M Blanc, FPA David, FG Van Der Goot, SwissPalm 2: Protein S-Palmitoylation Database, in: Maurine E. Linder (Ed.), Protein Lipidation: Methods and Protocols, Chapter 16. Methods in Mol Biol, 2009 2019, pp. 203-214.

[61] J Greaves, GR Prescott, OA Gorleku, LH Chamberlain, The fat controller: roles of palmitoylation in intracellular protein trafficking and targeting to membrane microdomains (Review), Mol Membrane Biol 26 (2009) 67-79.

[62] J Charollais, FG Van Der Goot, Palmitoylation of membrane protein (Review), Mol Membrane Biol 26 (2009) 55-66.

[63] T Sapir, M Segal, G Grigoryan, KM Hansson, P James, Reiner O Segal, The interactome of palmitoyl-protein theioesterase 1 (PPT1) affects neuronal morphology and function, Front Cell Neurosci 13 (2019) 92.

[64] N Yokoi, Y Fukata, A Sekiya, T Murakami, K Kobayashi, M Fukata, Identification of PSD-95 depalmitoylating enzymes, J Neurosci 36 (2016) 6431-6444.

[65] G Marwarha, S Rostad, J Lilek, M Kleinjan, J Schommer, O Ghribi, Palmitate increases B-site ABPP-cleavage enzyme 1 activity and amyloid-B genesis by evoking endoplasmic reticulum stress and subsequent C/EBP homologus protein activation, J Alzheimer's Dis 57 (2017) 907-925.

[66] DR Zamzow, V Elias, VA Acosta, E Escobedo, KR Magnusson, Higher levels of protein palmitoylation in the frontal cortex across aging were associated with reference memory and executive function declines, eNeuro 6 (2019) 1-15 e0310-18.

[67] DQ Tran, EK Tse, MH Kim, DD Belsham, Diet-induced cellular neuroinflammation in the hypothalamus: Mechanistic insights from investigation of neurons and microglia, Mol Cell Endo 438 (2016) 18-26.

[68] SC Benoit, CJ Kemp, CF Elias, W Abplanalp, JP Herman, S Migrenne, A-L Lefevre, C Cruciani-Guglielmacci C Magnan, F Yu, K Niswender, BG Irani, WL Holland, DJ Clegg, Palmitic acid mediates hypothalamic insulin resistance by altering PKCtheta subcellular localization in rodents, J Clin Invest 119 (2009) 2577-2589.

[69] CM Mayer, DD. Belsham, Palmitate attenuates insulin signaling and induces endoplasmic reticulum stress and apoptosis in hypothalamic neurons: rescue of resistance and apoptosis through Adenosine 5' Monophosphate-activated protein kinase activation, Endocrinology 151 (2010) 576-585.

[70] P Argente-Arizon, A Freire-Regatillo, J Argente, JA Chowen, Role of non-neuronal cells in body weight and appetite control, Front Endocrinol 6 (2015) 42.

[71] A Freire-Regatillo, P Argente-Arizon, J Argente, LM Garcia-Seguar, JA Chowen, Non-neuronal cells in the hypothalamic adaptation to metabolic signals, Front Endocrinol 8 (2017) 51.

[72] CT De Souza, EP Araujo, S Bordin, R Ashimine, RL Zollner, AC Boschero,
MJA Saad, LA Velloso, Consumption of a fat-rich diet activates a proinflammatory response and induces insulin resistance in the hypothalamus, Endocrinology 146 (2005) 4192-4199.

[73] M Milanski, G Degasperi, A Coope, J Morari, R Denis, DE Cintra, DML Tsukumo, G Anhe, ME Amaral, HK Takahashi, R Curi, HC Oliveira, JBC Carvalheira, S Bordin, MJ Saad, LA Velloso, Saturated fatty acids produce an inflammatory response predominantly through the activation of tlr4 signaling in hypothalamus: implications for the pathogenesis of obesity, J Neurosci 29 (2009) 359-370.

[74] L Cheng, Y Yu, A Szabo, Y Wu, H Wang, D Camer, X-F Huang, Palmitic acid induces central leptin resistance and impairs hepatic glucose and lipid metabolism in male mice, J Nutr Biochem 26 (2015) 541-548.

[75] M Valdearcos, MM Robblee, DI Benjamin, DK Nomura, AW Xu, SK Koliwad, Microglia dictate the impact of saturated fat consumption on hypothalamic inflammation and neuronal function, Cell Reports 9 (2014) 2124-2138.

[76] C Andre, Rey C Guzman-Quevedo, Clark S Remus-Borel, A Castellanos-Jankiewicz, E Ladeveze, T Leste-Lasserre, A Nadjar, DN Abrous, S Laye, S Cota, Inhibiting microglia explansion prevents diet-indcued hypothalamic and peripheral inflammation, Diabetes 66 (2017) 908-919.

[77] M Valdearcos, JD Douglass, MM Robblee, MD Dorfman, DR Stifler, ML Bennett, I Gerritse, R Fasnacht, BA Barres, JP Thaler, SK Koliwad, Microglial inflammatory signaling orchestrates the hypothalamic immune response to dietary excess and mediates obesity susceptibility, Cell Metab 26 (2017 Jul 5) 185-197.

[78] CM Duffy, C Yuan, LE Wisdorf, CJ Billington, CM Kotz, JP Nixon, TA Butterick, Role of orexin A signaling in dietary palmitic acid-activated microglial cells, Neurosci Lett 606 (2015) 140-144.

[79] CM Duffy, H Xu, JP Nixon, DA Bernlohr, TA Butterick, Identification of a fatty acid binding protein4-UCP2 axis regulating microglial mediated neuroinflammation, Mol Cell Neurosci 80 (2017) 52-57.

[80] R Wang, C Cruciani-Guglielmacci, S Migrenne, C Magnan, VE Cotero, VH Routh, Effects of oleic acid on distinct populations of neurons in the hypothalamic arcuate nucleus are dependent on extracellular glucose levels, J Neurophysiol 95 (2006) 1491-1498.

[81] S Obici, Z Feng, K Morgan, D Stein, Karkanias Ga, L Rossetti, Central administration of oleic acid inhibits glucose production and food intake, Diabetes 51 (2002) 271-275.

[82] C Hryhorczuk, Z Sheng, L Decarie-Spain, N Giguere, C Ducrot, L-E Trudeau, VH Routh, T Alquier, S Fulton, Oleic acid in the ventral tegmental area inhibits feeding, food reward, and dopamine tone, Neuropsychopharmacol 43 (2018) 607-616.

[83] EK Tse, DD. Belsham, Palmitate induces neuroinflammation, ER stress, and Pomc mRNA expression in hypothalamic mHypoA-POMC/GFP neurons through novel mechanisms that are prevented by oleate, Mol Cell Endo 472 (2018) 40-49.

[84] DC Guzman, NO Brizuela, MO Herrara, HJ Olguin, EH Garcia, AV Peraza, GB Mejia, Oleic acid protects against oxidative stress exacerbated by cytarabine and doxorubicin in rat brain, Anticancer Agents Med Chem 16 (2016) 1491-1495.

[85] K Brett, LV Kordyukova, MV Serebryakova, R Mintaev, AV Alexeevski, M Velt, Site-specific S-acylation of influenza virus hemagglutinin, J Biol Chem 289 (2014) 34978-34989.

[86] D Senyilmaz, S Virtue, X Xu, CY Tan, JL Griffin, AK Miller, A Vidal-Puig, AA Teleman, Regulation of mitochondrial morphology and function by stear oylation of TfR1, Nature 525 (2015) 124-128.

[87] I Syed, J Lee, PM Moraes-Vieira, CJ Donaldson, A Sontheimer, P Aryal, K Wellenstein, MJ Kolar, AT Nelson, D Siegel, J Mokrosinski, IS Farooqi, JJ Zhao, MM Yore, OD Peroni, A Saghatelian, BB Kahn, Palmitic acid hydroxystearic acids activate GPR40, which is involved in their beneficial effects on glucose homeostasis, Cell Metabolism 27 (2018) 419-427.

[88] C Song, C-H Shieh, Y-S Wu, A Kalueff, S Gaikwad, K-P Su, The role of omega-3 polyunsaturated fatty acids eicosapentaenoic and docosahexaenoic acids in the treatment of major depression and Alzheimer's disease: Acting separately or synergistically? Prog Lipid Res 62 (2016) 41-54.

[89] SI Liin, U Karlsson, BH Bentzen, N Schmitt, F Elinder, Polyunsaturated fatty acids are potent openers of human M-channels expressed in Xenopus laevis oocytes, Acta Physiologica 218 (2016) 28-37.

[90] AL Petursdottir, SA Farr, JE Morley, WA Banks, GV Skuladottir, Effect of dietary n3 polyunsaturated fatty acids on brain lipid fatty acid composition, learning ability, and memory of senescence-accelerated mouse, J Gerontol Biol Sci 63a (2008) 1153-1160.

[91] MA Perez, V Penaloza-Sancho, J Ahumada, M Fuenzalida, A Dagnino-Subiabre, n3 Polyunsaturated fatty acid supplementation restored impaired memory and GABAergic synaptic efficacy in the hippocampus of stressed rats, Nutr Neurosci 21 (2018) 556-569.

[92] F Aizawa, S Sato, F Yamazaki, I Yao, T Yamashita, K Nakamoto, F Kasuya, M Setou, S Tokuyama, N-3 fatty acids modulate repeated stress-evoked pain chronicity, Brain Res 1714 (2019) 218-226.

[93] T Inoue, M Tanaka, S Masuda, R Ohue-Kitano, H Yamakage, K Muranaka, H Wada, T Kusakabe, A Shimatsu, K Hasegawa, N Satoh-Asahara, Omega-3 polyunsaturaged fatty acids suppress the inflammatory responses of lipopolysaccharide-stimulated mouse microglia by activating SIRT1 pathways, Biochim Biophys Acta 1862 (2017) 552-560.

[94] X Chen, S Wu, C Chen, B Xie, Z Fang, W Hu, J Chen, H Fu, H He, Omega-3 polyunsaturated fatty acid supplementation attenuates microglial-induced inflammation by inhibiting the HMBG1/TLR4/NF-KB pathway following experimental traumatic brain injury, J Neuroinflamm 14 (2017) 143.

[95] S Wang, N Xiang, L Yang, C Zhu, X Zhu, L Wang, P Gao, Q Xi, Y Zhang, G Shu, $\mathrm{Q}$ Jiang, Linoleic acid and stearic acid elicit opposite effects on AgRP expression and secretion via TLR4-dependent signaling pathways in immortalized 
hypothalamic N38 cells, Biochem Biophys Res Comm 471 (2016) 566-571.

[96] SPH Alexander, A Christopoulos, AP Davenport, E Kelly, A Mathie, JA Peters, EL Veale, JF Armstrong, E Faccenda, SD Harding, AJ Pawson, JL Sharman, C Southan, JA Davies, The concise guide to pharmacology 2019/20: G proteincoupled receptors, Brit J Pharmacol 176 (2019) S21-S141.

[97] RG Pertwee, AC Howlett, SPH Alexander, V Di Marzo, MR Elphick, PJ Greasley, HS Hansen, G Kunos, K Mackie, R Mechoulam, RA Ross, International Union of Basic and Clinical Pharmacology. LXXIX. Cannabinoid receptors and their ligands: Beyond CB1 and CB2, Pharm Rev 62 (2010) 588-631.

[98] LA Matsuda, SJ Lolait, MJ Brownstein, AC Young, TI Bonner, Structure of a cannabinoid receptor and functional expression of the cloned cDNA, Nature 346 (1990) 561-564.

[99] S Munro, KL Thomas, M Abu-Shaar, Molecular characterization of a peripheral receptor for cannabinoids, Nature 365 (1993) 61-65.

[100] PV Piazza, D Cota, G Marsicano, The CB1 receptor as the cornerstone of exostasis, Neuron 93 (2017) 1252-1274.

[101] A Ligresti, L De Petrocellis, V Di Marzo, From phytocannabinoids to cannabinoid receptors and endocannabinoids: pleiotropic physiological and pathological roles through complex pharmacology, Physiol Rev 96 (2016) 1593-1659.

[102] M. Herkenham, Cannabinoid receptor localization in brain: Relationship to motor and reward systems, Ann New York Acad Sci 654 (1992) 19-32.

[103] M Herkenham, AB Lynn, MD Little, MR Johnson, LS Melvin, BR de Costa, KC Rice, Cannabinoid receptor localization in brain, PNAS USA 87 (1990) 1932-1936.

[104] I Katona, TF. Freund, Multiple functions of endocannabinoid signaling in the brain, Ann Rev Neurosci 35 (2012) 529-558.

[105] S Engeli, Central and peripheral cannabinoid receptors as therapeutic targets in the control of food intake and body weight appetite control, in: H-G Joost (Ed.), Springer Berlin Heidelberg, 2012, pp. 357-381 Editor.

[106] T.F. Freund, I. Katona, D. Piomelli, Role of endogenous cannabinoids in synaptic signaling, Physiological Reviews 83 (2003) 1017-1066.

[107] L Cristino, T Bisogno, V Di Marzo, Cannabinoids and the expanded endocannabinoid system in neurological disorders, Nature Rev Neurol 16 (2020) 9-29.

[108] R Rozenfeld, LA. Devi, Regulation of CB1 cannabinoid receptor trafficking by the adaptor protein AP-3, FASEB J 22 (2008) 2311-2322.

[109] M-A Djeungoue-Petga, E Hebert-Chatelain, Linking mitochondria and synaptic transmission: The CB1 receptor, Bioessays 39 (12) (2017) 1700126.

[110] E Hebert-Chatelain, T Desprez, R Serrat, L Bellocchio, E Soria-Gomez, A BusquetsGarcia, AC Pagano Zottola, A Delamarre, A Cannich, P Vincent, M Varilh, LM Robin, G Terral, MD García-Fernández, M Colavita, W Mazier, F Drago, N Nagore Puente, L Reguero, I Elezgarai, J-W Dupuy, D Cota, M-L LopezRodriguez, G Barreda-Gómez, F Massa, P Pedro Grandes, G Giovanni Bénard, G Marsicano, A cannabinoid link between mitochondria and memory, Nature 539 (2016) 555-559.

[111] C Stäubert, T. Schöneberg, GPCR signaling from intracellular membranes - a novel concept, Bioessays 39 (12) (2017) 1700200.

[112] M Koch, L Varela, JG Kim, JD Kim, F Hernandez-Nuno, SE Simonds, CM Castorena, CR Vianna, JK Elmquist, YM Morozov, P Rakic, I Bechmann, MA Cowley, K Szigeti-Buck, MO Dietrich, X-B Gao, S Diano, TL Horvath, Hypothalamic POMC neurons promote cannabinoid-induced feeding, Nature 519 (2015) 45-50.

[113] G Benard, F Massa, N Puente, J Lourenco, L Bellocchio, E Soria-Gomez, I Matias, A Delamarre, M Metna-Laurent, A Cannich, E Hebert-Chatelain, C Mulle, S OrtegaGutierrez, M Martin-Fontecha, M Klugmann, S Guggenhuber, B Lutz, J Gertsch, F Chaouloff, ML Lopez-Rodriguez, P Grandes, R Rossignol, G Marsicano, Mitochondrial CB(1) receptors regulate neuronal energy metabolism, Nat Neurosci 15 (2012) 558-564.

[114] A Gutierrez-Rodriguez, I Bonilla-Del Rio, N Puente, SM Gomez-Urquijo, CJ Fontaine, J Egana-Huguet, I Elezgarai, S Ruehle, B Lutz, LM Robin, E SoriaGomez, L Bellocchio, JD Padwal, M van der Stelt, J Mendizabal-Zubiaga, L Reguero, A Ramos, I Gerrikagoitia, G Marsicano, P Grandes, Localization of the cannabinoid type- 1 receptor in subcellular astrocyte compartments of mutant mouse hippocampus, Glia 66 (2018) 1417-1431.

[115] J Mendizabal-Zubiaga, S Melser, G Bénard, A Ramos, L Reguero, S Arrabal, I Elezgarai, I Gerrikagoitia, J Suarez, F Rodriguez de Fonseca, N Puente, G Marsicano, P Grandes, Cannabinoid CB(1) receptors are localized in striated muscle mitochondria and regulate mitochondrial respiration, Front Physiol 7 (2016) 476.

[116] A Drori, A Permyakova, R Hadar, S Udi, A Nemirovski, J Tam, Cannabinoid-1 receptor regulates mitochondrial dynamics and function in renal proximal tubular cells, Diabetes Obes Metab 21 (2019) 146-1459.
[117] I de Bus, R Witkamp, H Zuilhof, B Albada, M Balvers, The role of n-3 PUFA-derived fatty acid derivatives and their oxygenated metabolites in the modulation of inflammation, Prostaglandins Other Lipid Mediat 144 (2019) 106351.

[118] V. Di Marzo, New approaches and challenges to targeting the endocannabinoid system, Nature Reviews Drug Discovery 17 (2018) 623.

[119] Witkamp R. Fatty acids, endocannabinoids and inflammation, Eur J Pharmacol 785 (2016) 96-107.

[120] C Silvestri, V Di Marzo, The endocannabinoid system in energy homeostasis and the etiopathology of metabolic disorders, Cell Metabolism 17 (2013) 475-490.

[121] G Jager, RF. Witkamp, The endocannabinoid system and appetite: relevance for food reward, Nutr Res Rev 27 (2014) 172-185.

[122] N Weltens, I Depoortere, J Tack, L Van Oudenhove, Effect of acute $\Delta 9$-tetrahydrocannabinol administration on subjective and metabolic hormone responses to food stimuli and food intake in healthy humans: a randomized, placebo-controlled study, Am J Clin Nutr 109 (2019) 1051-1063.

[123] L. Bellocchio, P. Lafenêtre, A. Cannich, D. Cota, N. Puente, P. Grandes, et al., Bimodal control of stimulated food intake by the endocannabinoid system, Nature Neuroscience 13 (2010) 281-283.

[124] MR Mitchell, KC Berridge, SV Mahler, Endocannabinoid-enhanced "liking" in nucleus accumbens shell hedonic hotspot requires endogenous opioid signals, Cannabis Cannabinoid Res 3 (2018) 166-170.

[125] T.C. Kirkham, C.M. Williams, F. Fezza, V. Di Marzo, Endocannabinoid levels in rat limbic forebrain and hypothalamus in relation to fasting, feeding and satiation: Stimulation of eating by 2-arachidonoyl glycerol, British Journal of Pharmacology 136 (2002) 550-557.

[126] ANA Verty, WM Boon, PE Mallet, IS McGregor, BJ Oldfield, Involvement of hypothalamic peptides in the anorectic action of the CB1 receptor antagonist rimonabant (SR 141716), Eur J Neurosci 29 (2009) 2207-2216.

[127] P Cardinal, C Andre, C Quarta, L Bellocchio, S Clark, M Elie, T Leste-Lassere, M Maitre, C Gonzales, A Cannich, U Pagotto, G Marsicano, D Cota, CB1 cannabinoid receptor in SF1-expressing neurons of the ventromedial hypothalamus determines metabolic responses to diet and leptin, Mol Metab 3 (2014) 705-716.

[128] JD O'Hare, E Zielinski, B Cheng, T Scherer, C Buettner, Central endocannabinoid signaling regulates hepatic glucose production and systemic lipolysis, Diabetes 60 (2011) 1055-1062.

[129] L Cristino, R Imperatore, L Palomba, V Di Marzo, The endocannabinoid system in leptin-driven changes of orexinergic signaling under physiological and pathological conditions, in: M Melis (Ed.), Endocannabinoids and Lipid Mediators in Brain Functions, Springer International Publishing, Cham, 2017, pp. 1-26 Editor.

[130] NV DiPatrizio, KJ. Simansky, Activating parabrachial cannabinoid $\mathrm{CB}_{1}$ receptors selectively stimulates feeding of palatable foods in rats, J Neurosci 28 (2008) 9702-9709.

[131] E Soria-Gomez, L Bellocchio, L Reguero, G Lepousez, C Martin, M Bendahmane, S Ruehle, F Remmers, T Desprez, I Matias, T Wiesner, A Cannich, A Nissant, A Wadleigh, H-C Pape, AP Chiarlone, C Quarta, D Verrier, P Vincent, F Massa, B Lutz, M Guzman, H Gurden, G Ferreira, P-M Lledo, P Grandes, G Marsicano, The endocannabinoid system controls food intake via olfactory processes, Nature Neurosci 17 (2014) 407-415.

[132] NV. DiPatrizio, Endocannabinoids in the gut, Cannabis and Cannabinoid Research 1 (2016) 67-77.

[133] M.G.J. Balvers, K.C.M. Verhoeckx, S. Bijlsma, C.M. Rubingh, J. Meijerink, H.M. Wortelboer, et al., Fish oil and inflammatory status alter the n-3 to n-6 balance of the endocannabinoid and oxylipin metabolomes in mouse plasma and tissues, Metabolomics 8 (2012) 1130-1147.

[134] A. Berger, G. Crozier, T. Bisogno, P. Cavaliere, S. Innis, V. Di Marzo, Anandamide and diet: Inclusion of dietary arachidonate and docosahexaenoate leads to increased brain levels of the corresponding $\mathrm{N}$-acylethanolamines in piglets, Proceedings of the National Academy of Sciences of the United States of America 98 (2001) 6402-6406.

[135] HG Ly, J Ceccarini, N Weltens, G Bormans, K Van Laere, J Tack, L Van Oudenhove, Increased cerebral cannabinoid-1 receptor availability is a stable feature of functional dyspepsia: A [18 F]MK-9470 PET study, Psychotherapy and Psychosomatics 84 (2015) 149-158.

[136] J. Hirvonen, In vivo imaging of the cannabinoid CB1 receptor with positron emission tomography, Clin Pharmacol Ther 97 (2015) 565-567.

[137] J Ceccarini, N Weltens, HG Ly, J Tack, L Van Oudenhove, K Van Laere, Association between cerebral cannabinoid 1 receptor availability and body mass index in patients with food intake disorders and healthy subjects: a [(18)F]MK-9470 PET study, Translational Psychiatry 6 (7) (2016) e853. 